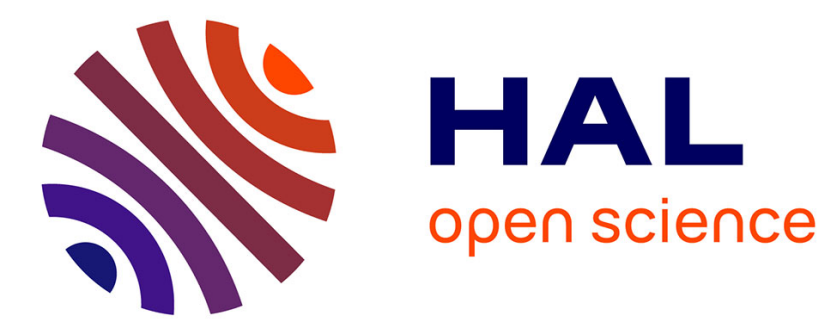

\title{
Nucleate boiling in a flat grooved heat pipe
}

Stéphane Lips, Frédéric Lefèvre, Jocelyn Bonjour

\section{To cite this version:}

Stéphane Lips, Frédéric Lefèvre, Jocelyn Bonjour. Nucleate boiling in a flat grooved heat pipe. International Journal of Thermal Sciences, 2009, 48, pp.1273-1278. 10.1016/j.ijthermalsci.2008.11.011. hal-01026184

\section{HAL Id: hal-01026184 \\ https://hal.science/hal-01026184}

Submitted on 18 Nov 2019

HAL is a multi-disciplinary open access archive for the deposit and dissemination of scientific research documents, whether they are published or not. The documents may come from teaching and research institutions in France or abroad, or from public or private research centers.
L'archive ouverte pluridisciplinaire HAL, est destinée au dépôt et à la diffusion de documents scientifiques de niveau recherche, publiés ou non, émanant des établissements d'enseignement et de recherche français ou étrangers, des laboratoires publics ou privés. 


\title{
Nucleate boiling in a flat grooved heat pipe
}

\author{
Stephane Lips, Frederic Lefevre* , Jocelyn Bonjour \\ CETHIL, UMR5008 CNRS-INSA-Univ. Lyon1, INSA-Lyon, 20 av. A. Einstein, \\ F-69621 Villeurbanne Cedex, France
}

\begin{abstract}
The present paper is devoted to an experimental study aiming at determining the thermal behaviour of a flat plate heat pipe (FPHP) with micro grooves and at focusing especially on the effect of boiling in the grooves. The FPHP is hermetically sealed on its upper face with a transparent plate for observations. Experimental results obtained with methanol are presented. Nucleate boiling in the grooves is observed for relatively small heat fluxes $\left(3 \mathrm{~W} \cdot \mathrm{cm}^{-2}\right)$. The onset of nucleate boiling improves the thermal performance of the flat heat pipe, and it must be emphasized that it does not constitute an operation limit as it is generally stated. The dry out of the evaporator is observed for heat fluxes much higher than the heat flux of onset of nucleate boiling. The results obtained for different filling ratios show the influence of this parameter that has to be optimized to improve the performance of the device.
\end{abstract}

Key words: Flat plate heat pipe; Nucleate boiling; Heat transfer capability; Thermal resistance; Micro grooves

\section{Nomenclature}

$\begin{array}{lll}H & \text { height } & \mathrm{m} \\ q & \text { heat flux } & \mathrm{W} \cdot \mathrm{cm}^{-2} \\ Q & \text { heat power } & \mathrm{W} \\ R & \text { thermal resistance } & \mathrm{K} \cdot \mathrm{W}^{-1} \\ T & \text { temperature } & \mathrm{K}\end{array}$

* Corresponding author. Tel:+33 472438251 Fax: +33 472438811

Email address: frederic.lefevre@insa-lyon.fr (Frederic Lefevre). 


$\begin{array}{llc}V & \text { volume } & \mathrm{m}^{3} \\ V^{*} & \text { volume ratio } & - \\ V_{0} & \text { dead volume } & \mathrm{m}^{3} \\ \text { Subscripts } & \\ \text { cond } & \text { condenser } \\ \text { evap } & \text { evaporator } \\ \text { gr } & \text { grooves } \\ \text { liq } & \text { liquid } \\ \text { max } & \text { maximum } \\ \text { min } & \text { minimum } \\ \text { sat } & \text { saturation }\end{array}$

\section{Introduction}

Flat plate heat pipes (FPHP) are micro-fluidic devices that are usually designed for the thermal management of electronic components $[1,2]$. They have also been used in others applications such as the cooling of fuel cells [3]. A flat plate heat pipe is a cavity of small thickness filled with a two-phase working fluid. One or several heat sources and heat sinks are located anywhere on the cavity with the other parts being insulated. Evaporation and condensation occur at the location of the heat sources and the heat sinks respectively. The liquid returns from the evaporator to the condenser through a capillary structure made of micro-grooves, meshes, or sintered powder wicks. Since the latent heat of evaporation is high, flat plate heat pipes are able to transfer high heat fluxes with small temperature gradients.

Although flat heat pipes are very efficient cooling systems, they are subject to a number of classical heat transfer limitations [4-6]: continuum flow limit, frozen start-up limit, viscous limit, sonic limit, entrainment limit, capillary limit, condenser limit and boiling limit. In the field of electronic cooling, working temperatures are in the range of $60^{\circ} \mathrm{C}$ and $120^{\circ} \mathrm{C}$. At this temperature level, the commonly used fluids are acetone, methanol, ethanol or water. In normal working conditions, continuum flow limit, frozen start-up limit, viscous limit, sonic limit and entrainment limit are not encountered. If the condenser is well designed and the heat pipe is free of non-condensable gas, the condenser limit is not encountered either.

The most commonly studied limitation in flat or miniature heat pipes is the capillary limit [2] that occurs when the sum of the liquid and vapour pressure 
drops exceeds the maximum capillary pressure that the capillary structure can sustain. If the heat flux at the evaporator is too high, the capillary or body forces available in the heat pipe may not be enough to drive a sufficient amount of liquid back to the evaporator. As a result, the liquid at the evaporator may be completely depleted until the dryout of the evaporator occurs. The experimental and theoretical results presented in [3,7] are a comprehensive example of a capillary driven flow in a flat grooved heat pipe, also sometimes called two-phase heat spreader. A confocal microscope was used to measure the meniscus curvature variation from the evaporator to the condenser for different heat fluxes including the maximum heat flux. Furthermore, temperature measurements were obtained along the grooves. Both measurements were used to validate a hydrodynamic model and a thermal model of a FPHP. 2D heat conduction thermal models of the condenser and the evaporator, depending on the meniscus curvature radii calculated in the hydrodynamic model, were developed. The comparisons with the experimental data showed the good ability of the numerical model to predict the maximum heat transport capability and the temperature field in the heat pipe.

For low heat fluxes, heat conduction based models, with vaporization or condensation at the liquid vapour interface are sufficient to calculate the temperature field. When the heat flux in the evaporator section becomes excessively high, nucleate boiling in the capillary structure can occur and thus modify the temperature field at the evaporator. If nucleate boiling is a normal working condition in gravity-assisted heat pipes, it is admit that "boiling in capillary driven heat pipes may severely affect the circulation of the fluid and lead to the boiling limit: large bubbles bursting at the liquid surface may disrupt the menisci established at the liquid-vapour interface and eliminate the capillary force circulating the liquid condensate" [5]. This limit is rarely described in the experimental or theoretical papers about flat plate heat pipes.

One can ask if nucleate boiling is actually not present in these experiments or if it is simply just not observed? Indeed, in most of the experimental works, FPHP are opaque and thus, the flow inside the capillary structure can not be observed. Only temperature measurements are provided to characterize the performance of the device [8-10]. As an example, Hopkins et al. [8], present a detailed experimental and theoretical analysis on maximum heat transfer capabilities of flat heat pipes in copper with micro grooves. In horizontal orientation, the heat flux reaches a maximum of $90 \mathrm{~W} . \mathrm{cm}^{-2}$ at a saturation temperature of $90^{\circ} \mathrm{C}$. This limitation is described as a capillary limitation and a capillary flow model is developed to calculate it. Recently, Chen et al. [11] presented an experiment with an open capillary structure (in non saturated atmosphere) heated at one extremity, the other extremity being in contact with a liquid reservoir. The authors observed both capillary flow from the reservoir to the heat source and nucleate boiling for rather small heat fluxes $\left(0.6 \mathrm{~W} . \mathrm{cm}^{-2}\right)$.

In this paper, an experimental study is presented to show the thermal behaviour of a flat grooved heat pipe, which is hermetically sealed on its upper 
face with a transparent plate for liquid/vapour meniscus observations. The applied heat fluxes permit the observation of nucleate boiling in the grooves and its consequences on the thermal performance of the flat heat pipe. In [3], nucleate boiling was not observed through the transparent wafer, because the capillary limit was reached for small heat fluxes (about $1 \mathrm{~W} . \mathrm{cm}^{-2}$ ) due to the large evaporator area. The proposed application was the cooling of fuel cell systems that involves a large heat source compared to the heat sink and the adiabatic region. Compared to the work presented in [3], the evaporating area is smaller with dimensions closed to that encountered in electronic cooling applications.

\section{Experimental set-up}

The flat heat pipe under investigation is shown in Fig. 1. Its capillary structure, of dimensions $70 \times 90 \mathrm{~mm}^{2}$, is made of 88 longitudinal micro-grooves, machined in a copper plate. Each groove has a rectangular cross-section of height and width equals to $400 \mu \mathrm{m}$. The distance between two grooves is equal to 400 $\mu \mathrm{m}$. The vapour space height is equal to $2 \mathrm{~mm}$ and the wall thickness under the grooves is equal to $3 \mathrm{~mm}$. The dimensions of the flat heat pipe have been optimised thanks to the numerical model of Lefevre et al. [7], that helps to reach a good trade-off beetween space requirement, capillary limit and thermal performance. The FPHP is hermetically sealed on its upper face with a transparent plate, which allows the liquid/vapour meniscus observation in the grooves. A high speed camera is used to visualize the flow. A filling copper pipe closed by a valve is sealed on the grooved plate at the extremity of the condenser.

The heat source is located on the copper wall (Fig. 2). It is a heated copper block of dimensions $70 \times 20 \mathrm{~mm}^{2}$ supplied by a $0-220 \mathrm{~V}$ AC power supply. Electric power is obtained by measuring the voltage across the heating resistor and the current, thanks to a calibrated resistance. Thus, the uncertainty due to the power measurement is negligible. The heat sink is a water heat exchanger of dimensions $30 \times 70 \mathrm{~mm}^{2}$. The water flow rate is constant and the inlet temperature is controlled by means of a thermostatic bath in order to have a constant working temperature when the heat input increases. The heat source and the heat sink are separated by an adiabatic area of length equal to $40 \mathrm{~mm}$. Two series of nine calibrated thermistors (uncertainty lower than $0.2 \mathrm{~K}$ ) are located symmetrically along the FPHP wall. They are fixed thanks to silver lacquer in small grooves that were machined in the wall in order to reduce the contact resistance (Fig. 1). The value of their resistance is recorded by a Keithley 2700 multimeter. The working temperature of the FPHP is the saturation temperature $T_{\text {sat }}$, which is determined as the mean temperature of the six thermistors located in the middle of the adiabatic zone. The FPHP 
is thermally insulated during the thermal tests.

Before the thermal tests, the FPHP has to be degassed and filled. In order to promote surface wetting, the copper plate is first cleaned. The FPHP and the working fluid are degassed carefully to eliminate the non-condensable gases. The method of evacuating the non-condensable gases from the working fluid is based on the fluid solidification under vacuum. The fluid contained in a heated vessel vaporizes, releases non-condensable gases and solidifies in a second vessel dipped into liquid nitrogen. The non-condensable gases are evacuated by vacuum pumps. The FPHP is degassed by heating during vacuum pumping at $10^{-6}$ mbar.

The volume of liquid inside the FPHP is measured at ambient temperature in vertical position, the filling tube being full of liquid. The filling ratio $V^{*}$ is de-

fined as the total liquid volume in the flat heat pipe $V_{\text {liq }}$ minus the dead volume due to the valve $V_{0}$, over the volume of the grooves $V_{\mathrm{gr}}: V^{*}=\left(V_{\mathrm{liq}}-V_{0}\right) / V_{\mathrm{gr}}$. $V_{0}$ and $V_{\text {gr }}$ are equal to $0.56 \mathrm{ml}$ and $1.27 \mathrm{ml}$ respectively.

\section{Experimental results}

The FPHP has been tested in horizontal orientation at a saturation temperature equal to $50{ }^{\circ} \mathrm{C}$. Temperatures are measured at successive increasing steps of heat flux and then at successive decreasing steps. At each step, temperatures are recorded when the steady state is reached. Thermal characterizations have been performed with three different filling ratios. Although the FPHP is thermally insulated, thermal losses lead to experimental uncertainties. In the present experimental conditions, their value has been estimated to be lower than $3 \mathrm{~W}$ for a saturation temperature of $50^{\circ} \mathrm{C}$. As a consequence, the relative uncertainty is important for small heat fluxes (about $10 \%$ for $2.5 \mathrm{~W} . \mathrm{cm}^{-2}$ ) but it can be neglected for high heat fluxes (lower than $2 \%$ for $13 \mathrm{~W} . \mathrm{cm}^{-2}$ ).

\subsection{Experimental results and flow observations at a fixed filling ratio}

In this part, the filling ratio $V^{*}$ is constant and equal to $2.8\left(V_{\text {liq }}=4.1 \mathrm{ml}\right)$. Fig. 3 and Fig. 4 show the temperature profiles along the flat heat pipe for increasing and decreasing heat fluxes respectively. The temperature field is nearly homogeneous at the evaporator due to the heated copper block, which tends to impose a temperature rather than a heat flux. For increasing and decreasing heat fluxes, the temperature field at the condenser are similar. At the evaporator, the temperatures increase for heat fluxes increasing from 1 to $9 \mathrm{~W} . \mathrm{cm}^{-2}$. Then, nucleate boiling appears inside the FPHP, which results in a clear drop off of the temperatures. For decreasing heat fluxes, nucleate boiling 
persists until about $3 \mathrm{~W} \cdot \mathrm{cm}^{-2}$. As a result, temperatures decrease continuously with decreasing heat fluxes. This temperature variation with increasing and decreasing heat fluxes can be interpreted as a conventional nucleate boiling hysteresis.

Fig. 5 shows the temperature field along the flat heat pipe with nucleate boiling (decreasing heat flux) and without nucleate boiling (increasing heat flux) for the same heat flux, namely $9.6 \mathrm{~W} . \mathrm{cm}^{-2}$. The decrease of temperature due to nucleate boiling may reach at most $5 \mathrm{~K}$ over the evaporator. Besides, Fig. 5 shows that nucleate boiling does not modify the thermal behavior of the adiabatic zone or the condenser.

Fig. 6 is a picture of the evaporator without (fig. 6a) and with (fig. 6b) nucleate boiling. Vapour bubbles are created at the bottoms of the grooves. They grow in the grooves and overflow. When their diameter reaches 1 to $2 \mathrm{~mm}$, they burst. Nucleate boiling does not prevent the flat heat pipe operation. The liquid is still drained from the condenser to the evaporator through the grooves, even with bubbles at the evaporator. Moreover, boiling increases the thermal efficiency of the flat heat pipe for two reasons. Nucleate boiling increases the evaporation heat transfer with respect to that obtained with evaporation at the liquid-vapour interface. Furthermore, the bubbles bursting permits wetting of the top of the fins that are normally dry, which highly improves heat transfer.

The thermal performance of the flat heat pipe can be characterized by the overall thermal resistance $R_{\text {tot }}=\left(T_{\max }-T_{\min }\right) / Q$, as well as the condenser and the evaporator thermal resistances $R_{\text {cond }}=\left(T_{\text {sat }}-T_{\min }\right) / Q$ and $R_{\text {evap }}=\left(T_{\max }-T_{\text {sat }}\right) / Q$ respectively. These thermal resistances are presented versus the heat flux in Fig. 7 for increasing and decreasing heat fluxes (indicated with arrows).

The overall thermal resistance variation is the result of the condenser and the evaporator thermal resistance variations. For increasing heat fluxes, $R_{\text {evap }}$ is sensibly constant until the heat flux reaches $12 \mathrm{~W} . \mathrm{cm}^{-2}$, which is the point of onset of nucleate boiling. Then, the thermal resistance noticeably decreases by almost $40 \%$. It has to be noticed that the maximum heat flux of $15 \mathrm{~W} . \mathrm{cm}^{-2}$ is a limitation of the test bench, and not a limitiation of the FPHP : at 15 W.cm ${ }^{-2}$, the heat sink temperature is close to $0^{\circ} \mathrm{C}$ and it is not possible to test the FPHP for higher heat fluxes with the same saturation temperature. For decreasing heat fluxes, nucleate boiling persists until $3 \mathrm{~W} . \mathrm{cm}^{-2}$, which results in lower thermal resistances than for increasing heat fluxes. Nevertheless, the thermal resistance decreases with the decrease of the heat flux, because the number of active nucleation sites is progressively reduced. The condenser thermal resistance does not significantly depend on the choice of increasing or decreasing the heat flux. It decreases with the increase of the heat flux in both cases, which can be explained by an increase of the condensation area 
with the decrease of the heat sink temperature.

One can notice that the thermal performance of the condenser is better for a heat flux of $1 \mathrm{~W} . \mathrm{cm}^{-2}$ than for $2 \mathrm{~W} . \mathrm{cm}^{-2}$. This can be explained by a reorganisation of the liquid load inside the condenser, that has been observed through the transparent plate during the experiments. Indeed, depending of the conditions, some zones can be over-flooded up to the transparent plate (Fig. 8). In non working conditions, the liquid tends to form a disk-shaped drop at the center of the heat pipe. Some liquid is also trapped in the corners of the flat heat pipe (Fig. 8a). For low heat fluxes, the liquid leaves the evaporator corners and is mainly located on the condenser side. Vapour flow pushes the liquid disk until its junction with the condenser liquid load (Fig. 8b). For higher heat fluxes, the liquid-vapour interface of the liquid load evolves as a function of the pressure gradient in the vapour flow (Fig. 8c and 8d). Reorganization of the liquid load in the condenser has a noticeable effect on heat transfer: the zones that are full of liquid exhibit a higher thermal resistance than the others. Thus, from a thermal point of view, the shape of $8 \mathrm{a}$ performs better than that shape of $8 \mathrm{c}$. It has to be noticed that the grooves are not totally flooded except in the condenser even if the filling ratio is greater than unity. The liquid fills the grooves and forms meniscii whose curvature radius varies all along the grooves. Thus, in the adiabatic and evaporator area, capillary forces allow the liquid flow from the condenser to the evaporator.

\subsection{Influence of the filling ratio on the thermal performance}

The FPHP performance has been determined for three different filling ratios (Table 1). $H$ is the liquid height measured when the FPHP is in vertical position.

Fig. 9 shows the overall thermal resistance versus the heat flux for the different filling ratios. Whatever the heat flux, the thermal performance obtained for a filling ratio of 2.8 is worse than that obtained for a filling ratio of 1.6. Indeed, condensation cannot occur in the portions of the condenser that are full of liquid and by consequence the condenser thermal resistance decreases with the filling ratio. The flooding area can be estimated by visualization through the transparent plate. For a filling ratio of 2.8 , about $60 \%$ of the condenser area is full of liquid whereas the flooding area can be considered as negligible for a filling ratio equal to 1.3. Hence, the filling ratio of 1.3 leads to the smallest condenser thermal resistance. However, even through a filling ratio of 1.3 leads to the best performance for low heat fluxes, it leads to the worst performance for high heat fluxes.

Fig. 10 shows the boiling curves for the different filling ratios. The wall superheat is defined as the difference between the maximal temperature (hottest 
spot) and the saturation temperature. The curves for filling ratios of 2.8 and 1.6 are quite similar, while the wall superheat is higher for a filling ratio of 1.3. Indeed, for low filling ratios, the liquid load is not sufficient to completely reflood the grooves when nucleate boiling occurs, which results in a partial dryout of the grooves after bubble burst, even for moderate heat fluxes. One can notice that for a filling ratio of 1.3, the boiling curve for both increasing and decreasing heat fluxes are identical when the heat flux is smaller than 12 W. $\mathrm{cm}^{-2}$. The wall superheat at the onset nucleate boiling decreases when the filling ratio decreases. It reaches about $19 \mathrm{~K}\left(12 \mathrm{~W} . \mathrm{cm}^{-2}\right)$ for a filling ratio of $2.8,15 \mathrm{~K}\left(9 \mathrm{~W} . \mathrm{cm}^{-2}\right)$ for a filling ratio of 1.6 , and only $6 \mathrm{~K}\left(3 \mathrm{~W} . \mathrm{cm}^{-2}\right)$ for a filling ratio of 1.3 (Fig. 9). For decreasing heat fluxes, nucleate boiling stops for $3 \mathrm{~W} . \mathrm{cm}^{-2}$ whatever the filling ratio.

These experiments show the nucleate boiling in the grooves improves the thermal performance of a flat heat pipe. It does not constitute an operation limit. Nevertheless, if the heat flux is too high, dryout appears at the evaporator for heat fluxes lower than the capillary limit. Indeed, applying the model of Lefevre et al. [7] that was validated with a very similar flat heat pipe for lower heat fluxes leads to a capillary limit equal to $18 \mathrm{~W} . \mathrm{cm}^{-2}$. During the present experiments, partial dryout of the evaporator end is observed for heat fluxes greater than $12 \mathrm{~W} . \mathrm{cm}^{-2}$ for a filling ratio of 1.6 and $9 \mathrm{~W} . \mathrm{cm}^{-2}$ for a filling ratio of 1.3 .

Fig. 11 is a view obtained thanks to a high speed camera of a zone of the evaporator for a heat flux of $15 \mathrm{~W} . \mathrm{cm}^{-2}$ and a filling ratio of 1.6. Three different behaviors can be observed: near the adiabatic section, heat transfer is lead by thin film evaporation phenomenon. In the middle of the evaporator, nucleate boiling is preponderant. Lastly a dryout zone appears at the extremity of the evaporator, which increases the evaporator thermal resistance (Fig. 9 and Fig. 10). The line of dryout drawn on Fig. 11 is very stable during the time, but its position differs in increasing or decreasing heat fluxes: the dryout area is higher for decreasing heat fluxes than for increasing heat fluxes.

An optimum filling ratio exists in order to minimize the thermal resistance of the flat heat pipe. Indeed, the condenser thermal resistance decreases when the filling ratio decreases but a low filling ratio can increase the evaporator thermal resistance and decrease the dryout heat flux. Fig. 12 shows the temperature profile along the grooves for a heat flux equal to $9.6 \mathrm{~W} . \mathrm{cm}^{-2}$, for decreasing heat fluxes and for the three filling ratios. For a filling ratio of 1.3 , the condenser thermal resistance is small but there is an important evaporator thermal resistance. On the contrary, for a filling ratio of 2.8, the thermal resistance is high on the condenser side but low on the evaporator side. An intermediate filling ratio of 1.6 is a good trade-off with small thermal resistances in both the evaporator and the condenser. It seems to be an optimum filling ratio for this flat heat pipe. 


\section{Conclusions}

A flat plate heat pipe, sealed with a transparent plate, has been tested for different filling ratios and for different heat fluxes. Various phenomena have been highlighted, and especially the occurrence of the boiling phenomenon. It appears that boiling has a noticeable impact on the heat transfer at the evaporator and consequently on the FPHP temperature field. A nucleate boiling hysteresis is also observed through the temperature field in the FPHP. For increasing heat fluxes, the heat flux at onset of nucleate boiling depends on the filling ratio and ranges from 3 to $12 \mathrm{~W} \cdot \mathrm{cm}^{-2}$ whereas for decreasing heat fluxes, nucleate boiling stops at $3 \mathrm{~W} . \mathrm{cm}^{-2}$ whatever the filling ratio. The experiments show that boiling does not prevent the operation of the FPHP even in presence of fully developed boiling phenomenon, but on the contrary, improves the heat transfer. For high heat fluxes, dryout occurs at the extremity of the evaporator. The dryout heat flux depends on the filling ratio and ranges, for the studied FPHP, from $9 . \mathrm{cm}^{-2}$ to $12 \mathrm{~W} . \mathrm{cm}^{-2}$. Besides, it has been shown that the filling ratio also has a great effect on the condenser heat transfer and that an optimal filling ratio exists in order to minimize the thermal resistance. All these investigations have been made under normal gravity. But heat pipes are often used in space applications : it would be interesting to perform identical tests under micro gravity, in order to determine if the conclusions of this study can be generalized in this case. Anyway, a better understanding of these phenomena is necessary, in particularly to predict theoretically the operation limit in case of nucleate boiling.

\section{References}

[1] L. Vasiliev, Micro and miniature heat pipes - electronic component coolers, Applied Thermal Engineering 28 (2008) 266-273.

[2] M. Lallemand, F. Lef ${ }^{\circ}$ vre, Micro/mini heat pipes for the cooling of electronic devices, in: 13th Int. Heat Pipe Conference, Shangai, China, 2004, pp. 12-23.

[3] R. Rulli ${ }^{\circ}$ re, F. Lef ${ }^{\circ}$ vre, M. Lallemand, Prediction of the maximum heat transfer capability of two-phase heat spreaders - experimental validation, Int. J. Heat Mass Transfer 50 (2007) 1255-1262.

[4] P. Dunn, D. Reay, Heat pipes, Pergamon press, Oxford, 1978.

[5] A. Faghri, Heat pipe science and technology, Taylor and Francis, 1994.

[6] G. Peterson, An introduction to heat pipes, Wiley \& sons, New-York, 1994.

[7] F. Lef ${ }^{\circ}$ vre, R. Rulli ${ }^{\circ}$ re, G. Pandraud, M. Lallemand, Prediction of the temperature field in two-phase heat spreaders with microgrooves - experimental validation, Int. J. Heat Mass Transfer, In Press. 
[8] R. Hopkins, A. Faghri, D. Khrustalev, Flat miniature heat pipes with micro capillary grooves, J. Heat Transfer 121 (1999) 102-109.

[9] Y. Cao, M. Gao, Experiments and analyses of flat miniature heat pipes with micro capillary grooves, J. Heat Transfer 11 (2) (1997) 158-164.

[10] S. J. Kim, J. K. Seo, K. H. Do, Analytical and experimental investigation on the operational characteristics and the thermal optimization of a miniature heat pipe with a grooved wick structure, Int. J. Heat Mass Transfer 46 (2003) 2051-2063.

[11] S. W. Chen, J. C. Hsieh, C. T. Chou, H. H. Lin, S. C. Shen, M. J. Tsai, Experimental investigation and visualization on capillary and boiling limits of micro-grooves made by different processes, Sensors and Actuators A 139 (2007) $78-87$. 


\section{Figure Captions}

Figure 1: Schematic of the FPHP

Figure 2: Schematic of the flat heat pipe test apparatus

Figure 3: Temperature profiles along the FPHP for increasing heat fluxes

Figure 4: Temperature profiles along the FPHP for decreasing heat fluxes

Figure 5: Effect of nucleate boiling on the temperature field $\left(q=9.6 \mathrm{~W} . \mathrm{cm}^{-2}\right)$

Figure 6: Evaporator observations in working conditions

Figure 7: Thermal resistances versus heat flux $\left(T_{\text {sat }}=50^{\circ} \mathrm{C}\right)$

Figure 8: Location of the flooded zones in the flat heat pipe for $V^{*}=2.8$

Figure 9: Influence of the filling ratio on the overall thermal resistance $\left(T_{\text {sat }}=\right.$ $\left.50^{\circ} \mathrm{C}\right)$

Figure 10: Boiling curves for different filling ratios

Figure 11: Visualisation of the partial dryout on an evaporator zone

Figure 12: Temperatures along the grooves for decreasing heat fluxes $(q=9.6$ W.cm ${ }^{-2}$ ) 

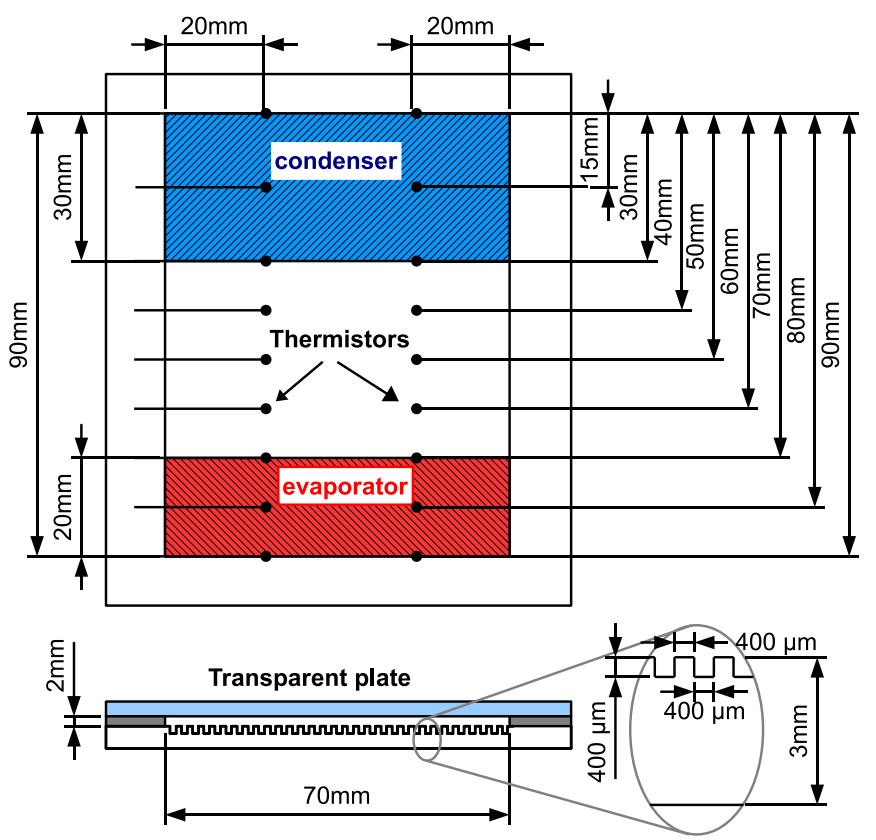

Fig. 1. Schematic of the FPHP 


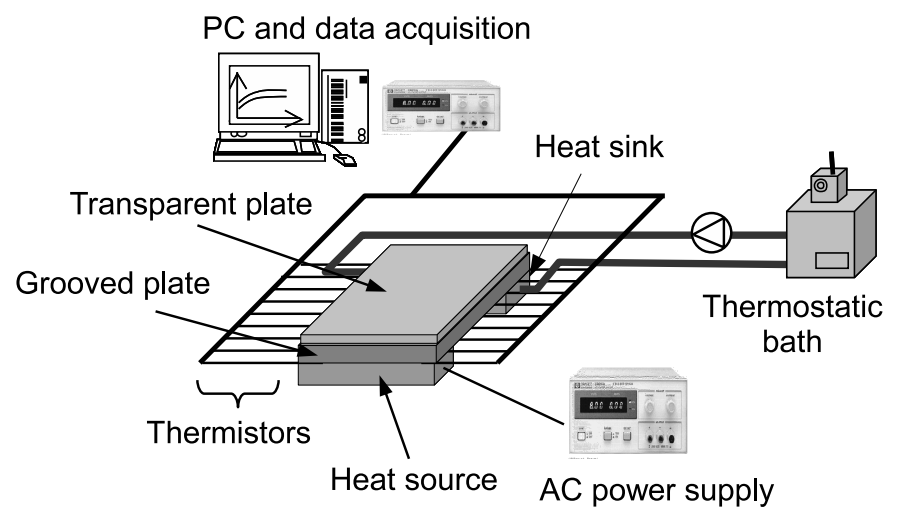

Fig. 2. Schematic of the flat heat pipe test apparatus 


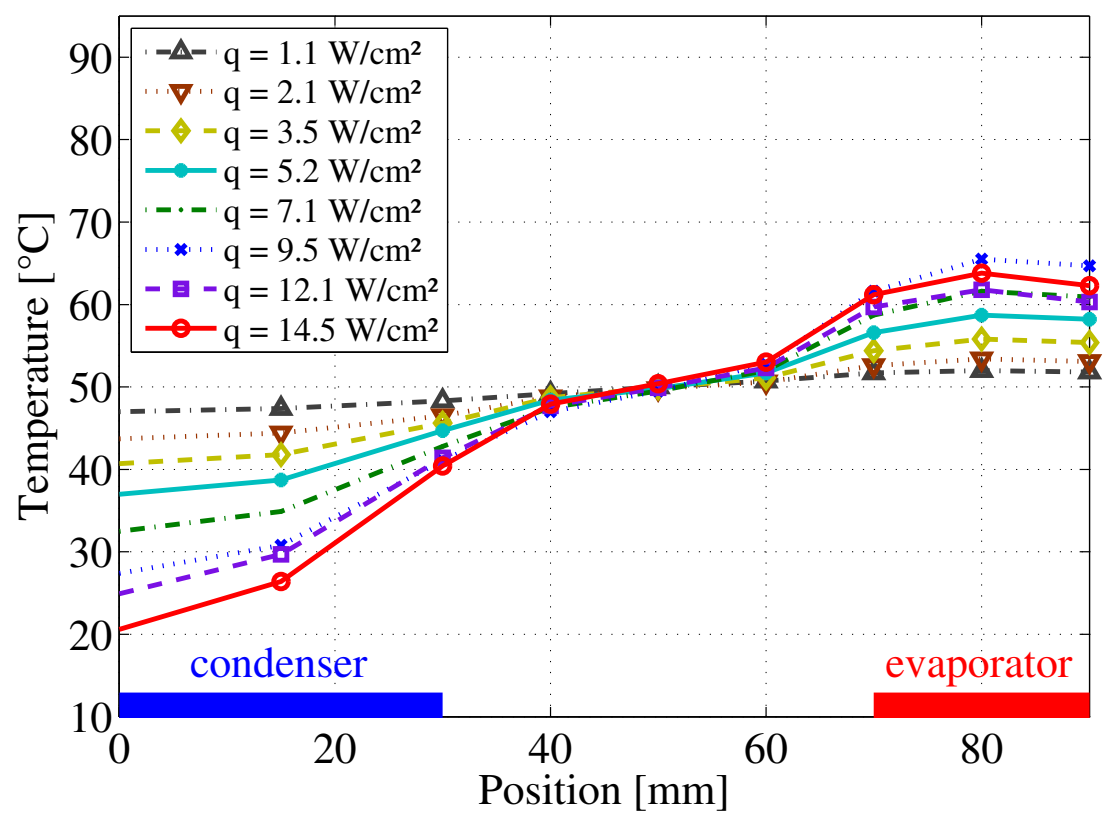

Fig. 3. Temperature profiles along the FPHP for increasing heat fluxes 


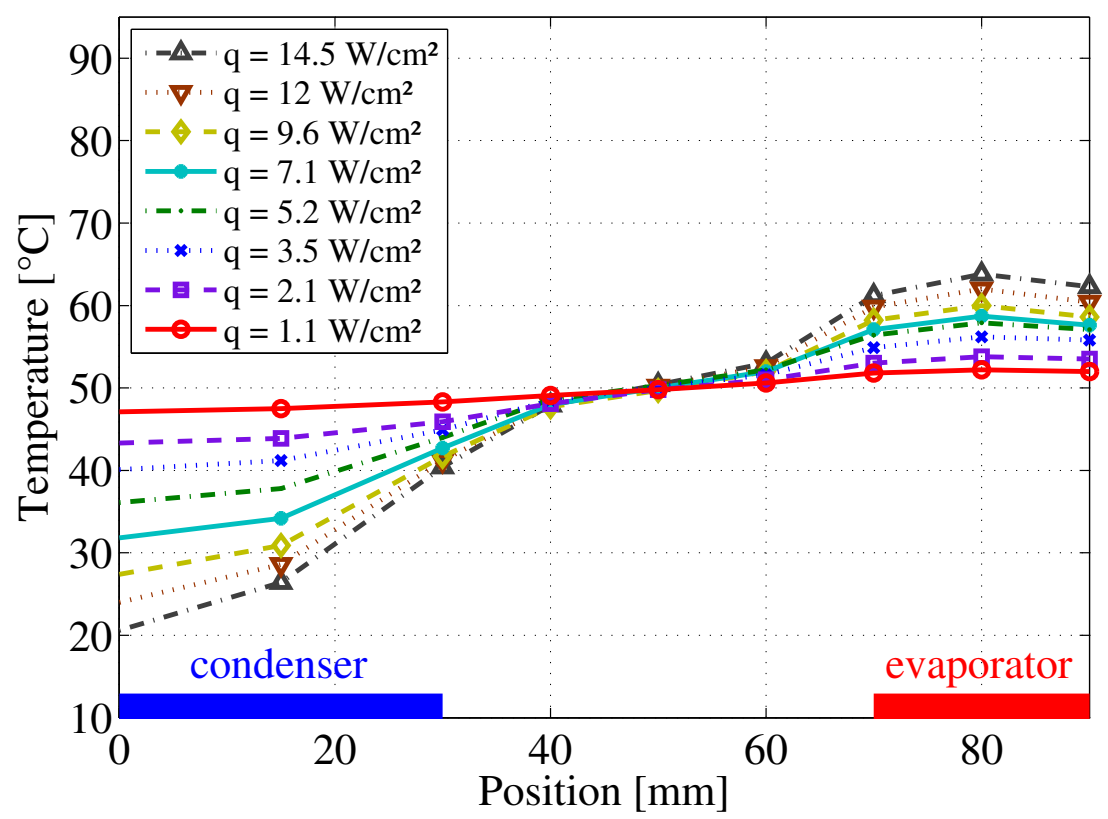

Fig. 4. Temperature profiles along the FPHP for decreasing heat fluxes 


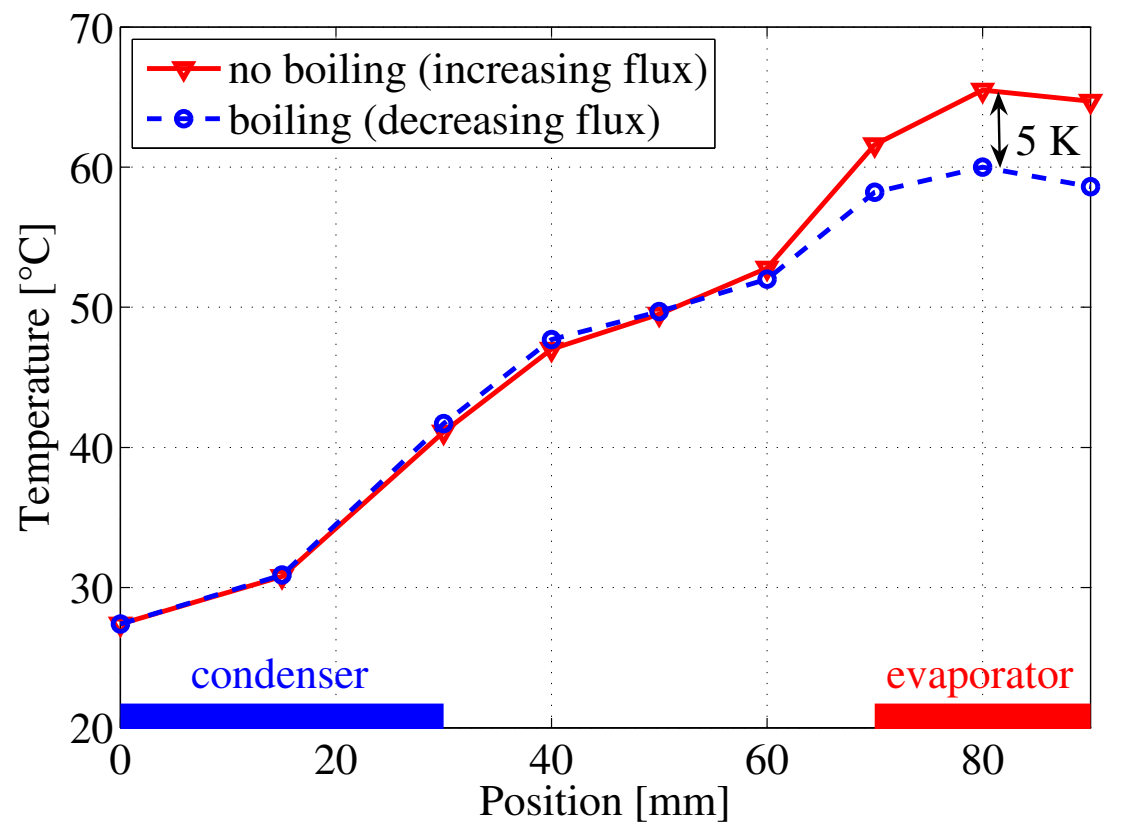

Fig. 5. Effect of nucleate boiling on the temperature field $\left(q=9.6\right.$ W.cm $\left.{ }^{-2}\right)$ 


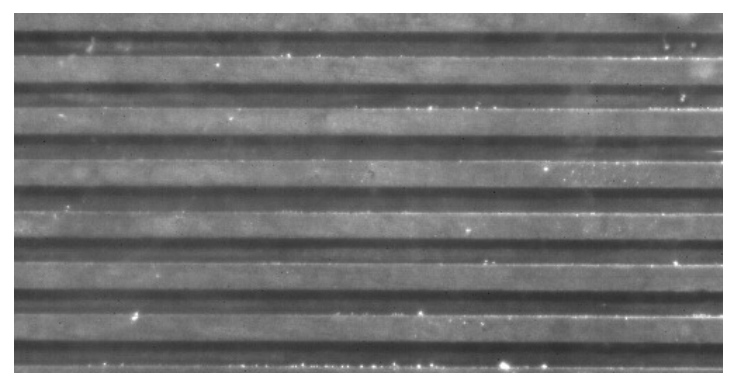

a) Evaporator zone without boiling

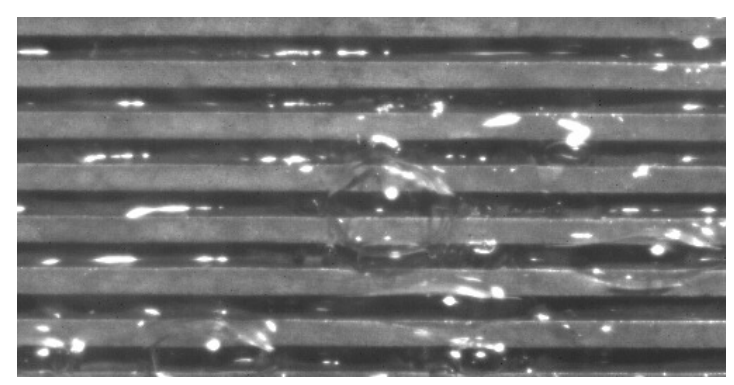

b) Evaporator zone with boiling

Fig. 6. Evaporator observations in working conditions 


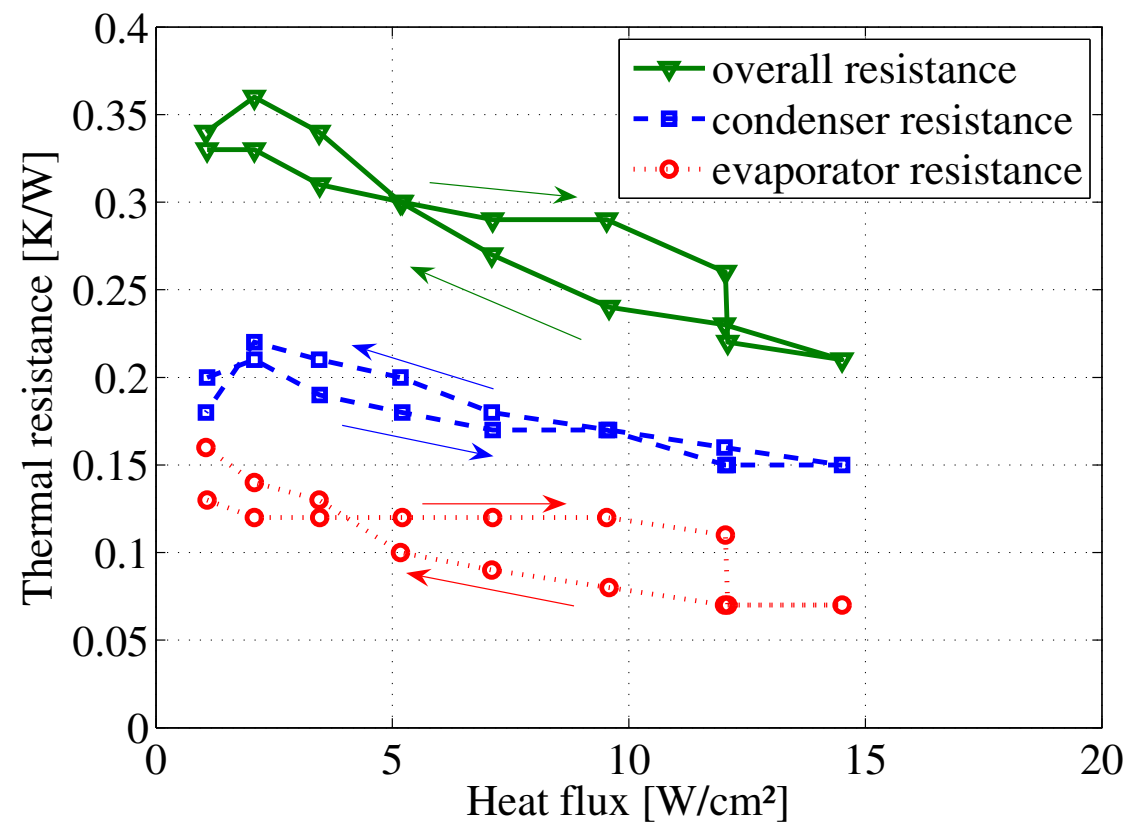

Fig. 7. Thermal resistances versus heat flux $\left(T_{\text {sat }}=50^{\circ} \mathrm{C}\right)$ 


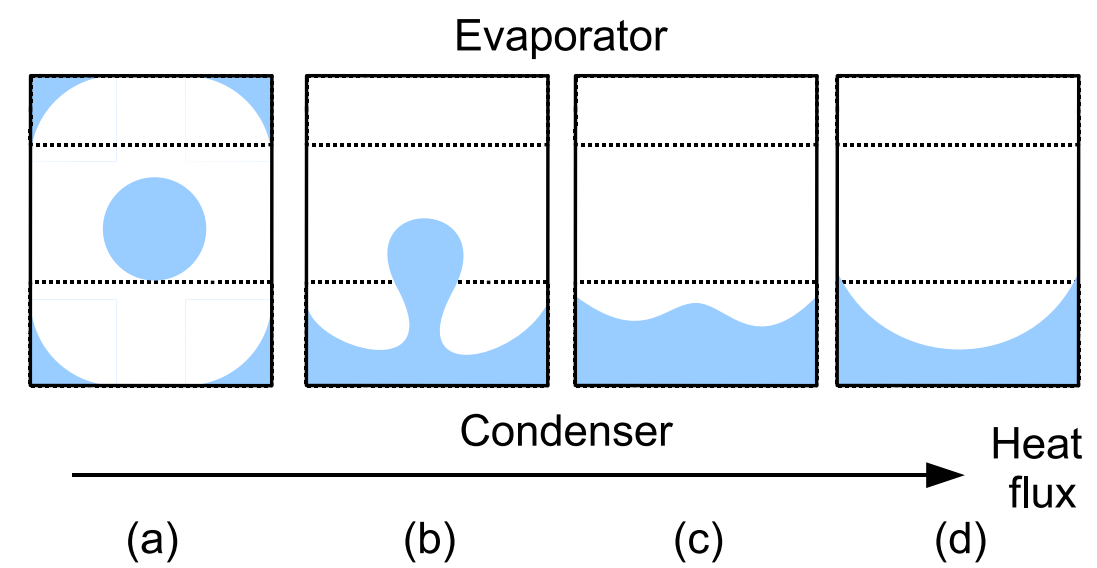

Fig. 8. Visualization of the flooded zones in the flat heat pipe through the transparent plate for $V^{*}=2.8$ 


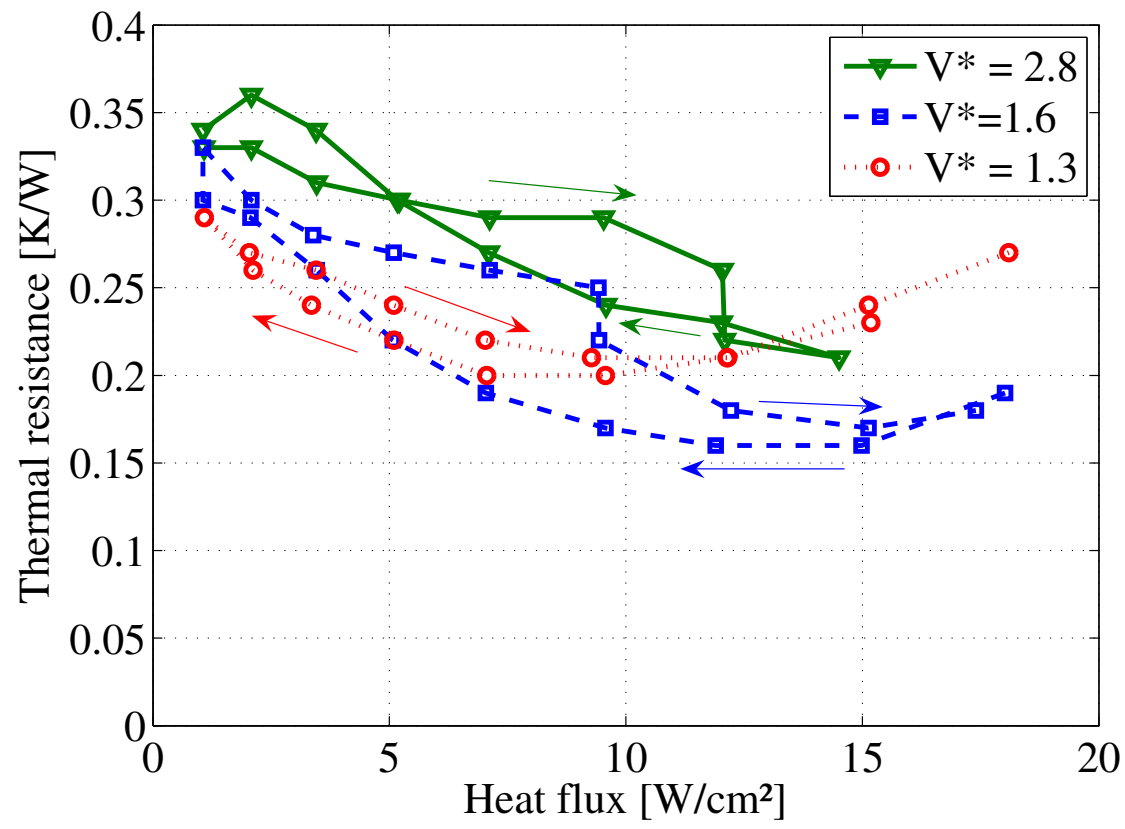

Fig. 9. Influence of the filling ratio on the overall thermal resistance $\left(T_{\text {sat }}=50^{\circ} \mathrm{C}\right)$ 


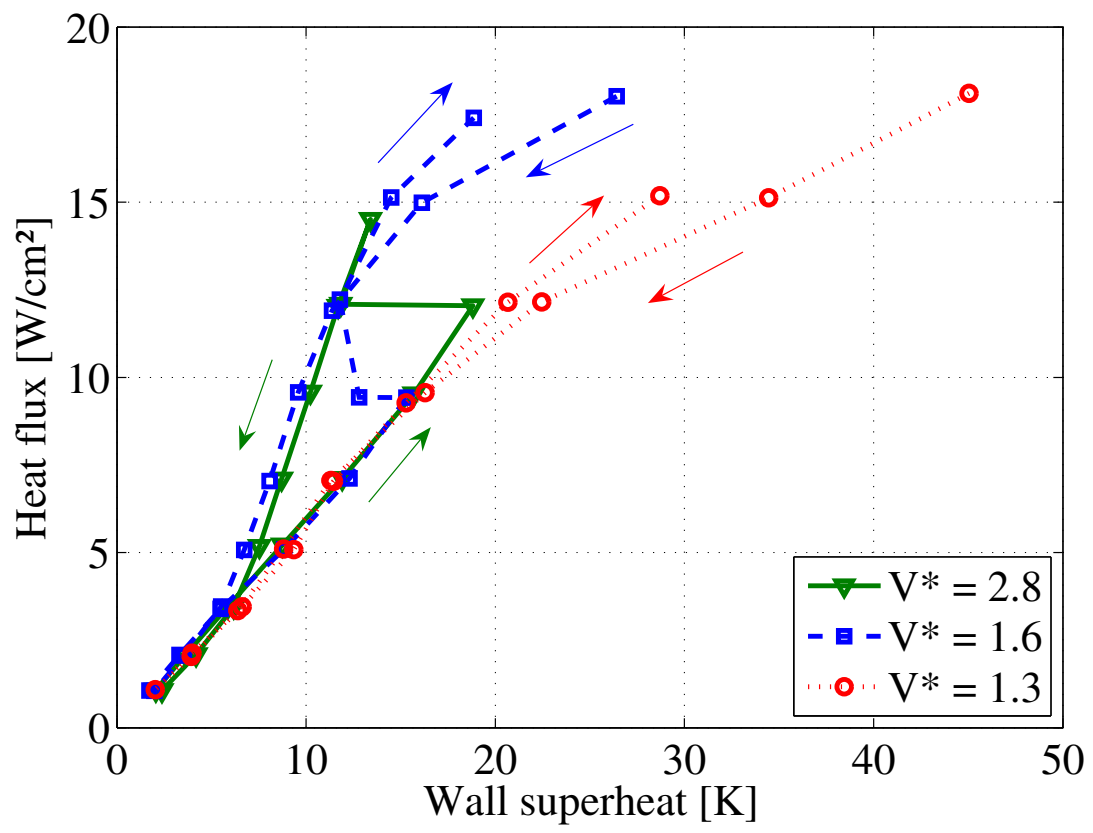

Fig. 10. Boiling curves for different filling ratios 


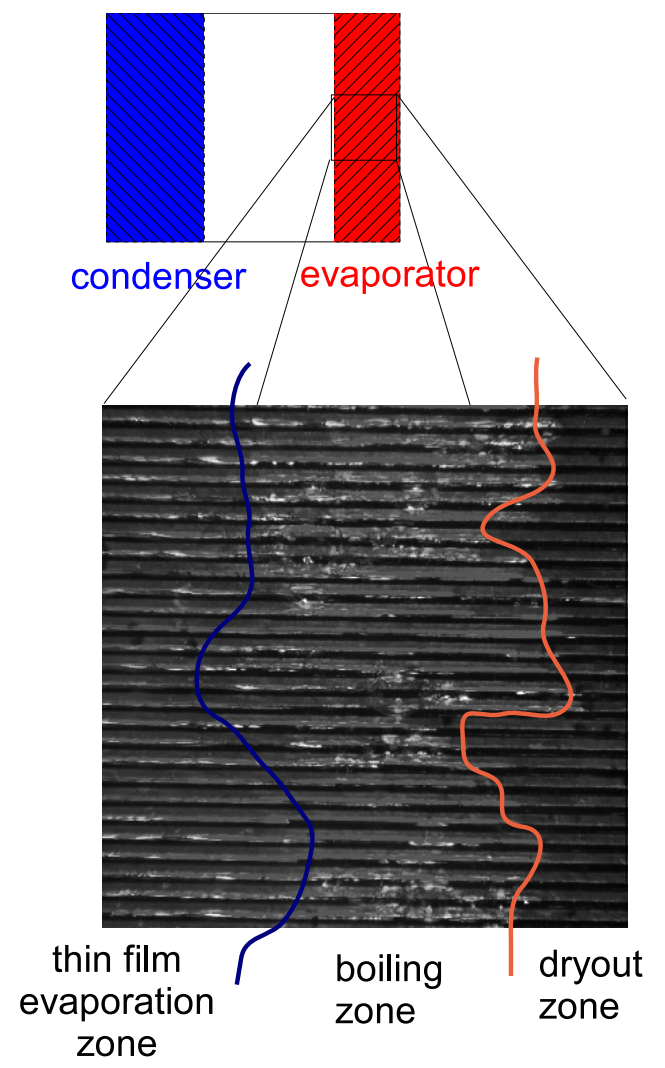

Fig. 11. Visualisation of the partial dryout on an evaporator zone 


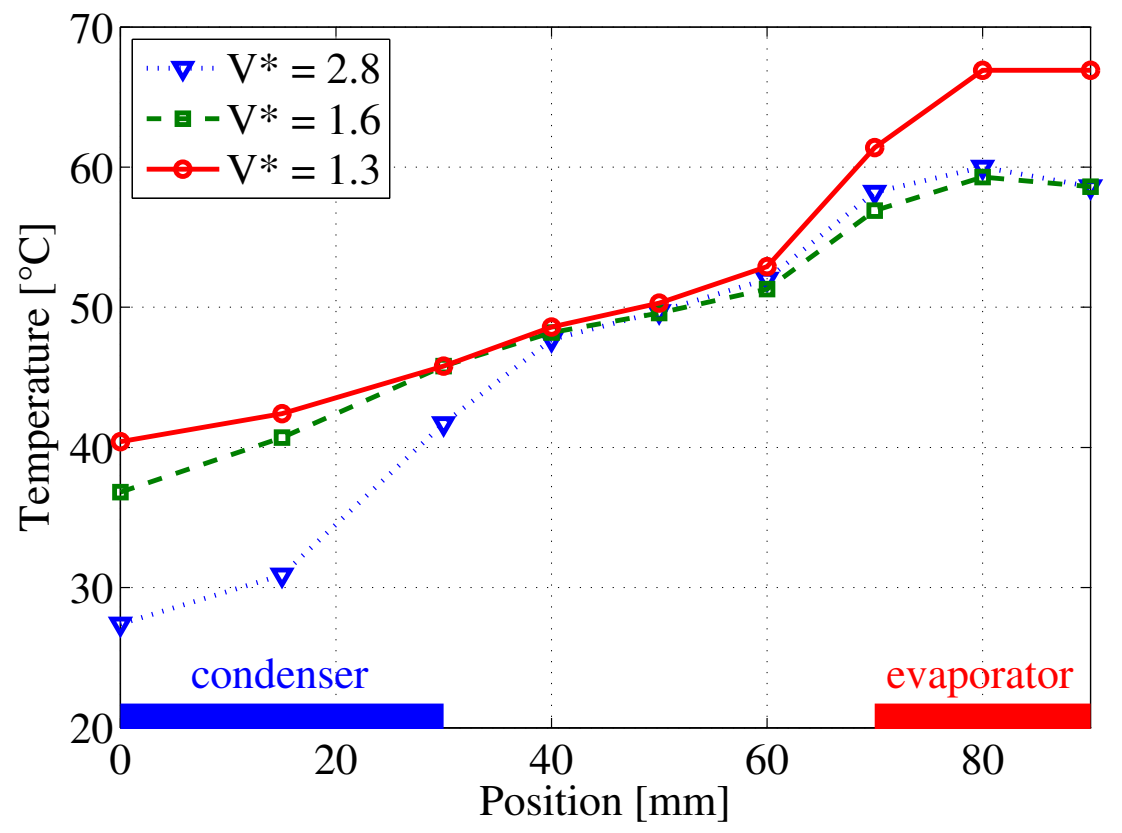

Fig. 12. Temperatures along the grooves for decreasing heat fluxes $\left(q=9.6 \mathrm{~W} . \mathrm{cm}^{-2}\right)$ 
Table 1

Determination of the filling ratio

\begin{tabular}{|c|c|c|}
\hline$H[\mathrm{~cm}]$ & $V_{\text {liq }}[\mathrm{ml}]$ & $V^{*}[-]$ \\
\hline 2 & 4.1 & 2.8 \\
1 & 2.6 & 1.6 \\
0.7 & 2.2 & 1.3 \\
\hline
\end{tabular}

